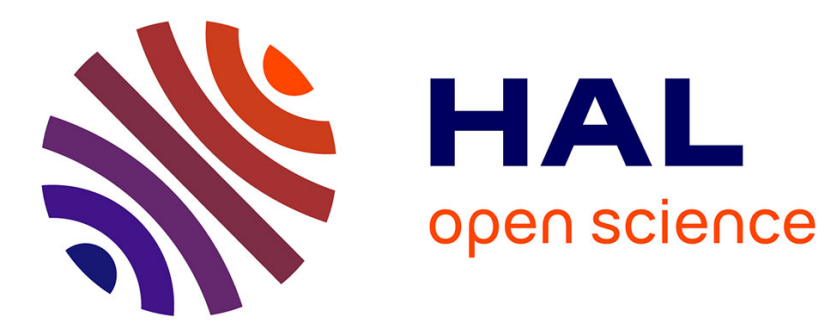

\title{
Neutron scattering study of the reorientational motions for NH3 groups in (NH3(CH2)3NH3) MnCl 4
}

\author{
Jean-Christophe Sourisseau, G. Lucazeau, A.J. Dianoux
}

\section{To cite this version:}

Jean-Christophe Sourisseau, G. Lucazeau, A.J. Dianoux. Neutron scattering study of the reorientational motions for $\mathrm{NH} 3$ groups in $(\mathrm{NH} 3(\mathrm{CH} 2) 3 \mathrm{NH} 3) \mathrm{MnCl} 4$. Journal de Physique, 1983, 44 (8), pp.967-974. 10.1051/jphys:01983004408096700 . jpa-00209680

\section{HAL Id: jpa-00209680 https://hal.science/jpa-00209680}

Submitted on 1 Jan 1983

HAL is a multi-disciplinary open access archive for the deposit and dissemination of scientific research documents, whether they are published or not. The documents may come from teaching and research institutions in France or abroad, or from public or private research centers.
L'archive ouverte pluridisciplinaire HAL, est destinée au dépôt et à la diffusion de documents scientifiques de niveau recherche, publiés ou non, émanant des établissements d'enseignement et de recherche français ou étrangers, des laboratoires publics ou privés. 
Classification

Physics Abstracts

$35.20 \mathrm{Y}-64.70 \mathrm{~K}$

\title{
Neutron scattering study of the reorientational motions for $\mathrm{NH}_{3}$ groups in $\left(\mathrm{NH}_{3}\left(\mathrm{CH}_{2}\right)_{3} \mathrm{NH}_{3}\right) \mathrm{MnCl}_{4}$
}

\author{
C. Sourisseau, \\ Laboratoire de Spectrochimie Infrarouge et Raman, 2, rue Henri-Dunant, 94320 Thiais, France \\ G. Lucazeau, \\ Université Paris-Nord, Laboratoire de Chimie Physique, avenue J. B.-Clément, 93430 Villetaneuse, France
}

and A. J. Dianoux

Institut Laue-Langevin, 156 X, Centre de Tri, 38042 Grenoble, France

(Reçu le 11 janvier 1983, révisé le 17 mars, accepté le 28 avril 1983)

\begin{abstract}
Résumé. - Des expériences de diffusion incohérente quasi-élastiquedes neutrons ont été réalisées à partir de cristaux orientés et d'échantillons polycristallins des composés $\left(\mathrm{NH}_{3}\left(\mathrm{CH}_{2}\right)_{3} \mathrm{NH}_{3}\right) \mathrm{MnCl}_{4}$ et $\left(\mathrm{NH}_{3}\left(\mathrm{CD}_{2}\right)_{3} \mathrm{NH}_{3}\right) \mathrm{MnCl}_{4}$ sur le domaine de température 4-300 $\mathrm{K}$. Des spectromètres à rétro-diffusion et à temps de vol ont été utilisés; les spectres ont été enregistrés à l'aide de différentes résolutions (entre 1 et $170 \mu \mathrm{eV}$ ) et sur un large domaine de transfert de moment (entre 0,17 et $2,57 \AA^{-1}$ ).

On conclut que les groupes $\mathrm{NH}_{3}$ effectuent des mouvements de réorientation en dessous de $300 \mathrm{~K}$. Les spectres expérimentaux ont été reproduits, de manière satisfaisante, par un modèle de sauts de $2 \pi / 3$ des groupes $\mathrm{NH}_{3}$, avec un temps de corrélation de $10^{-11} \mathrm{~s}$ à $300 \mathrm{~K}$ et une énergie d'activation d'environ $27 \mathrm{~kJ} / \mathrm{mole}$.

Enfin, une comparaison de ces résultats avec ceux de la littérature, provenant essentiellement d'études antérieures par RMN et Raman, est présentée.
\end{abstract}

\begin{abstract}
Incoherent quasi-elastic neutron scattering experiments have been performed on oriented crystals and on polycrystalline samples of $\left(\mathrm{NH}_{3}\left(\mathrm{CH}_{2}\right)_{3} \mathrm{NH}_{3}\right) \mathrm{MnCl}_{4}$ and $\left(\mathrm{NH}_{3}\left(\mathrm{CD}_{2}\right)_{3} \mathrm{NH}_{3}\right) \mathrm{MnCl}_{4}$ compounds in the 4-300 $\mathrm{K}$ temperature range. Backscattering and time of flight spectrometers were used; spectra were obtained using different resolutions $(1-170 \mu \mathrm{eV})$ and a large range of momentum transfers $\left(0.17-2.57 \AA^{-1}\right)$.

It is concluded that $\mathrm{NH}_{3}$ groups reorientate below $300 \mathrm{~K}$; the experimental spectra have been satisfactorily fitted with a model of $2 \pi / 3$ jumps of the $\mathrm{NH}_{3}$ groups, associated with a correlation time of $1 \times 10^{-11} \mathrm{~s}$ at $300 \mathrm{~K}$ and an activation energy roughly equal to $27 \mathrm{~kJ} / \mathrm{mol}$.

Finally a comparison with literature data, mainly from NMR and Raman results, is presented.
\end{abstract}

\section{Introduction.}

The propylene diammonium metal tetrachloride layer compounds having formula $\left(\mathrm{NH}_{3}\left(\mathrm{CH}_{2}\right)_{\mathbf{n}} \mathbf{N H}_{3}\right) \mathbf{M C l}_{\mathbf{4}}$ with $n=2,3,4,5$ and $\mathrm{M}=\mathrm{Cu}, \mathrm{Mn}, \mathrm{Fe}, \mathrm{Cd}, \ldots$ belong to the perovskite structural family. Their magnetic properties $[1,2]$ and their structural phase transitions have been extensively studied $[2,6]$. These compounds crystallize in a two dimensional structure consisting of nearly isolated layers of corner-sharing $\mathrm{MCl}_{6}$ octahedra parallel to the $(a, c)$ planes. The interlayer bonding in the $b$-direction is only achieved by the alkylene-diammonium cations through $\mathrm{NH}$... Cl hy- drogen bonds. For the 1-3 propylenediammonium manganese tetrachloride compound (Fig. 1), noted hereafter as PDA $\mathrm{MnCl}_{4}$, the sequence of phase transitions presented in table I results from calorimetric [3] and Raman experiments [7]. The structures of the corresponding phases have been investigated by different authors :

(i) Willet and Riedel [2], from a neutron diffraction study, have shown that the room temperature phase III is disordered. Also, from broad line proton NMR measurements, they conclude that this disorder is of a dynamical nature, the PDA ions undergoing rotational motions around their long $b$-axes. 
Table I. - Phase sequence and structural data on PDA $\mathrm{MnCl}_{4}$.

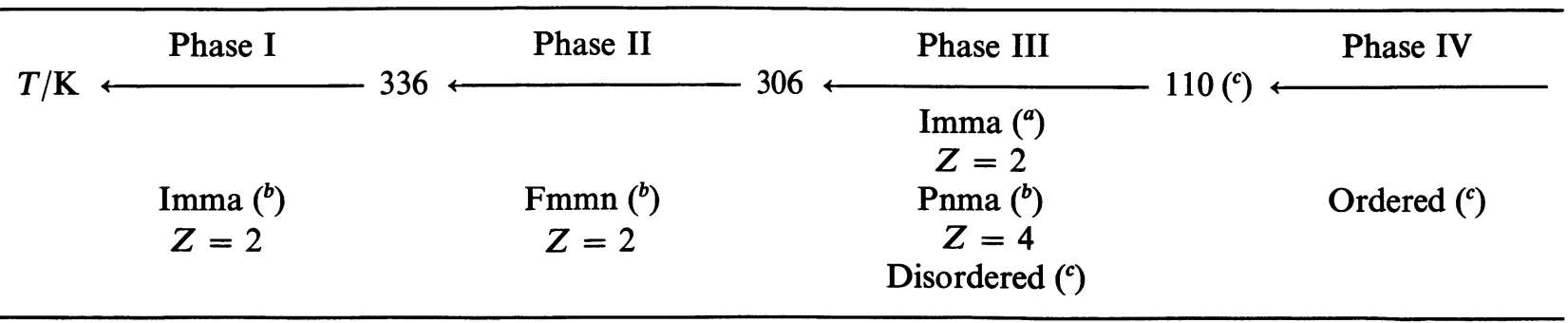

\footnotetext{
$Z$ gives the primitive unit cell multiplicity,

$\left({ }^{a}\right)$ from ref. [2],

$($ b) from ref. [5],

(c) from ref. [7].
}

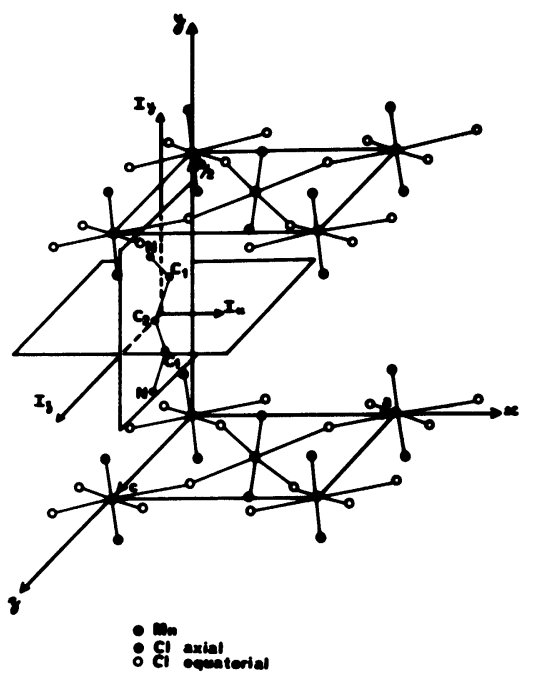

Fig. 1. - Simplified picture of the structure of $\left(\mathrm{NH}_{3}\left(\mathrm{CH}_{2}\right)_{3} \mathrm{NH}_{3}\right) \mathrm{MnCl}_{4}$ showing two layers of $\mathrm{MnCl}_{6}$ octahedra and only the skeleton of one propylene diammonium cation (hydrogen atoms are omitted).

(ii) Sourisseau and Lucazeau [6, 7], from an infrared and Raman study, have shown that the fully ordered phase is obtained below $100 \mathrm{~K}$ and that at about $110 \mathrm{~K}$ a phase transition must occur; this low temperature ordered phase was identified as phase IV. From a systematic study of the temperature dependence of Raman frequencies and half-widths, it was concluded that the dynamical disorder is associated with $\mathrm{NH}_{3}$ groups below $300 \mathrm{~K}$. Assuming that the broadening of Raman bands is entirely due to $\mathrm{NH}_{3}$ jumps, an activation energy of $4.2 \mathrm{~kJ} / \mathrm{mol}$ was derived and found similar to the six fold potential barrier $\left(V_{6} \simeq 5.02 \mathrm{~kJ} / \mathrm{mol}\right)$ associated with the $\mathrm{NH}_{3}$ torsional movements. However no arguments were given to rule out the possibility of a three fold barrier $V_{3} \simeq$ $20.08 \mathrm{~kJ} / \mathrm{mol}$ [7]. Above $110 \mathrm{~K}$, it is believed that $\mathrm{NH}_{3}$ movements are coupled with reorientations of PDA ions and that this could explain the observation

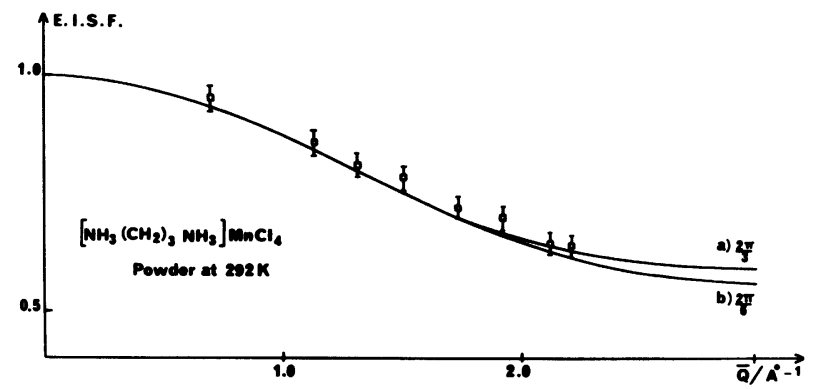

Fig. 2. - Comparison of the theoretical (full-lines) and experimental (市 points) EISF for different reorientational movements of the $\mathrm{NH}_{3}$ mobile protons in powdered samples. a) on a circle of radius $0.942 \AA$ for $2 \pi / 3$ jumps, b) on a circle of radius $0.942 \AA$ for $2 \pi / 6$ jumps.

of a unique N-H stretching frequency. There will be in a first approximation an equiprobability of the possible positions of PDA ions. Above $336 \mathrm{~K}$ (phase I), from the point of view of their long axis rotational degree of freedom, PDA and $\mathrm{NH}_{3}$ groups are in a quasi liquid state.

(iii) Kind, Plesko and Roos [5] have concluded from NQR and NMR experiments that in phase III the chains are almost ordered and are in one out of the four potential wells of the cavity. These four orientations exist within an unit cell and are related by symmetry operations of the Pnma group. A dynamical disorder of the chains between two orientations was only observed above $306 \mathrm{~K}$. Moreover these authors do not observe at low temperature any anomaly in their ${ }^{35} \mathrm{Cl} \mathrm{NQR}$ frequencies and conclude that there is no phase transition at $110 \mathrm{~K}$ as proposed in reference 7 .

We have thus undertaken incoherent quasi-elastic neutron scattering (IQENS) experiments in order to get a better insight into the dynamical disorder, in particular to evaluate to what extent the PDA ions are involved. Our preliminary neutron scattering results on PDA $\mathrm{MnCl}_{4}$ (using ${ }^{12} \mathrm{H}$ and ${ }^{6} \mathrm{D}^{6} \mathrm{H}$ derivatives) have already been reported $[8,9]$. 


\section{Experimental conditions.}

Polycrystalline samples of $\left(\mathrm{NH}_{3}\left(\mathrm{CH}_{2}\right)_{3} \mathrm{NH}_{3}\right) \mathrm{MnCl}_{4}$ [2] and $\left(\mathrm{NH}_{3}\left(\mathrm{CD}_{2}\right)_{3} \mathrm{NH}_{3}\right) \mathrm{MnCl}_{4}$ [10] compounds were freshly prepared and controlled by infrared spectroscopy before and after IQENS experiments in order to check that neither hydratation nor H/D exchange had taken place. Powder samples were contained in circular thin walled aluminium cans ( $5 \mathrm{~cm}$ in diameter) and their thickness was adjusted to ensure a transmission of about $90 \%$. Oriented mosaic samples composed of platelet crystals (with the $(a, c)$ basal plane) were also contained in slab shaped aluminium containers and they were oriented either at $135^{\circ}\left(Q_{\|}\right)$or at $45^{\circ}\left(Q_{\perp}\right)$ with respect to the incident beam (Fig. 3). The measured transmissions in these cases were found equal to only $75 \%$.

Neutron scattering experiments were performed at the Institut Laue-Langevin (ILL, Grenoble, France) with the backscattering (BS) high resolution IN10 instrument and the time of flight (TOF) IN5 and IN6 spectrometers [11]. The experimental conditions are summarized in table II. In the BS instrument seven detectors were set at scattering angles between $2 \theta=9.75^{\circ}$ and $153^{\circ}$. Ten detector positions ranging
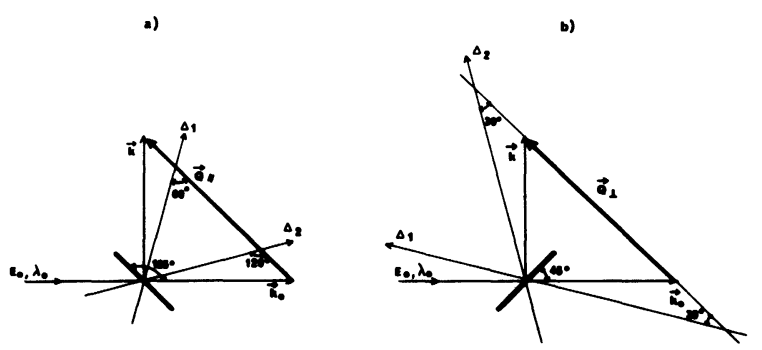

Fig. 3. - Schematic drawing of the orientations of the monocrystalline platelets with respect to the incident neutron beam. a) $3 \pi / 4$ configuration called " $Q$ parallel » to the layer planes $\left.\left(Q_{\|}\right), b\right) \pi / 4$ configuration called " $Q$ perpendicular" to the layer planes $\left(Q_{\perp}\right), \Delta_{1}$ and $\Delta_{2}$ are the axes of rotation for the $\mathrm{NH}_{3}$ groups with respect to the base planes. from $2 \theta=23.5^{\circ}$ to $129^{\circ}$ were used in the IN5 TOF spectrometer while sixteen and twenty four counters at angles between $2 \theta=12^{\circ}$ and $114^{\circ}$ were utilized in the IN6 TOF spectrometer with incident wavelengths $5.9 \AA$ and $4.1 \AA$, respectively. Angles that were contaminated by Bragg reflections were eliminated from the data. The spectra were corrected by standard programs for detector efficiency, sample container efficiency, scattering absorption and self-shielding $[12,13]$. A BS spectrum of the sample at $4 \mathrm{~K}$ was used as a resolution run while all the TOF spectra were normalized to the elastic scattering from vanadium.

\section{Theoretical background and EISF curves.}

The incoherent scattering law, $S_{\text {inc }}(Q, w)$ for a polycrystalline sample in the quasi-elastic region takes the form

$$
\begin{aligned}
S_{\text {inc }}(Q, w)=\exp \left(-Q^{2}\right. & \left.\left\langle u^{2}\right\rangle\right) \times \\
\times & \left\{S_{\text {inc }}^{\text {rot }}(Q, w)+B(Q)\right\},
\end{aligned}
$$

were the first term is the Debye-Waller factor in which $\left\langle u^{2}\right\rangle$ is the mean square hydrogen vibrational amplitude and $B(Q)$ is the inelastic background contribution. The rotational scattering function, $S_{\text {inc }}^{\text {rot }}(Q, w)$ has been calculated for different models of proton reorientations and the problem of random one dimensional rotation in a $N$-fold cosine potential has been treated by Dianoux and Volino [14, 15]. Here we will however use the simple rotational jump model. In this model of rotational jumps between a finite number $N$ of allowed sites, the scattering law consists of an elastic term and a series of broadened terms. It takes the following form for a powder sample [16].

$S_{\mathrm{inc}}^{\mathrm{rot}}(Q, w)=A_{0}(Q) \delta(w)+\frac{1}{\pi} \sum_{i=1}^{N-1} A_{i}(Q) L\left(\tau_{i}^{-1}\right)$.

where

$A_{i}(Q)=\frac{1}{N} \sum_{p=1}^{N} j_{0}\left(2 Q a \sin \frac{\pi p}{N}\right) \times \cos \left(\frac{2 \pi i p}{N}\right)$,

\begin{tabular}{|c|c|c|c|c|c|}
\hline $\begin{array}{l}\text { Compound } \\
\text { (geometry) }\end{array}$ & Instrument & $\begin{array}{l}\text { Incident } \\
\text { wavelength } \\
(\AA)\end{array}$ & $\begin{array}{l}\text { Resolution } \\
\text { FWHM } \\
(\mu \mathrm{eV})\end{array}$ & $\begin{array}{l}\text { Temperature } \\
\text { range } \\
(\mathrm{K})\end{array}$ & $\begin{array}{l}\text { Momentum } \\
\text { range } \\
\left(\AA^{-1}\right)\end{array}$ \\
\hline $\begin{array}{l}\left(\mathrm{NH}_{3}\left(\mathrm{CD}_{2}\right)_{3} \mathrm{NH}_{3}\right) \mathrm{MnCl}_{4} \\
\left(\mathrm{NH}_{3}\left(\mathrm{CH}_{2}\right)_{3} \mathrm{NH}_{3}\right) \mathrm{MnCl}_{4} \\
\text { Powders }\end{array}$ & IN10 & 6.28 & 1.0 & $4-280$ & $0.17-1.95$ \\
\hline $\begin{array}{l}\left(\mathrm{NH}_{3}\left(\mathrm{CH}_{2}\right)_{3} \mathrm{NH}_{3}\right) \mathrm{MnCl}_{4} \\
\text { Platelets }\left(135^{\circ} \text { and } 45^{\circ}\right) \\
\text { Powders }\left(45^{\circ}\right)\end{array}$ & $\begin{array}{l}\text { IN5 } \\
\text { IN5 }\end{array}$ & $\left\{\begin{array}{r}10.05 \\
5.14 \\
5.14\end{array}\right.$ & $\begin{array}{r}20 \\
130 \\
130\end{array}$ & $\begin{array}{c}250-304 \\
250-304 \\
292\end{array}$ & $\begin{array}{l}0.25-1.13 \\
0.49-2.21 \\
0.49-2.21\end{array}$ \\
\hline $\begin{array}{l}\left(\mathrm{NH}_{3}\left(\mathrm{CH}_{2}\right)_{3} \mathrm{NH}_{3}\right) \mathrm{MnCl}_{4} \\
\text { Platelets }\left(135^{\circ} \text { and } 45^{\circ}\right)\end{array}$ & IN6 & $\left\{\begin{array}{l}5.9 \\
4.1\end{array}\right.$ & $\begin{array}{r}68 \\
170\end{array}$ & $\begin{array}{l}299 \\
299\end{array}$ & $\begin{array}{l}0.24-1.75 \\
0.32-2.57\end{array}$ \\
\hline
\end{tabular}

Table II. - Experimental conditions. 
$j_{0}$ is the spherical Bessel function of the first kind of order zero $\left(j_{0}(x)=\frac{\sin x}{x}\right)$ and $L\left(\tau_{i}^{-1}\right)$ is a Lorentzian function,

$$
L\left(\tau_{i}^{-1}\right)=\frac{\tau_{i}}{1+w^{2} \tau_{i}^{2}}
$$

in which $\tau_{i}^{-1}$ is the HWMH and the characteristic times are given by

$$
\tau_{i}=\frac{\tau_{\mathrm{c}}}{2 \sin ^{2}\left(\frac{\pi \cdot i}{N}\right)},
$$

where $\tau_{\mathrm{c}}$ is the correlation time between two successive jumps of a proton. It is known [14-16] that the first term of broadening in the summation over all the possible jumps gives the largest contribution and thus, the experimental HWHM of the quasi-elastic peaks may be sometimes approximated by $1 / \tau_{1}$. Moreover, in the limiting case $N \rightarrow \infty$, this jump probability can be identified with the rotational diffusion coefficient, $D_{\mathrm{r}}$. The term $A_{0}(Q)$ in the above expression 2 represents the elastic incoherent structure factor, EISF; it is the purely elastic fraction of the integrated elasticplus-quasielastic intensity. The EISF is directly related to the geometry of the molecular motion and is a measure of the time averaged spatial distribution of the protons [17]. EISF values as a function of $\bar{Q}\left(\AA^{-1}\right)$ can be compared with the calculated ones for different models. In fact, $2 \pi / 3$ and $2 \pi / 6$ are the most probable jump angles for uniaxial rotation of $\mathrm{NH}_{3}$ groups in PDA $\mathrm{MnCl}_{4}$. Thus, figure 2 shows the theoretical EISF curves for a random walk of $\mathrm{N}-\mathrm{H}$ protons among 3 and 6 equidistant sites on a circle of radius $a=0.942 \AA$ assuming that the $\mathrm{CH}_{2}$ backbone of the PDA ion is rigidly fixed. Under these conditions, the theoretical expression is

$$
\text { EISF }=\rho+(1-\rho) A_{0}(Q),
$$

where $\rho$ is the ratio of the number of fixed protons to the total number of protons. As the $\mathrm{NH}_{3}$ groups exhibit a very small radius of gyration we cannot discriminate between both jump models within the $Q$ range used but, from the good agreement with the experimental points, we conclude that only half of the protons $(\rho=0.5)$ in PDA cations are involved in the dynamical process. These protons are surely those of $\mathrm{NH}_{3}$ groups since a (weak) broadening in the quasielastic region has been observed in the high resolution experiments using the deuterated powder sample $\left(\mathrm{NH}_{3}\left(\mathrm{CD}_{2}\right)_{3} \mathrm{NH}_{3}\right) \mathrm{MnCl}_{4}$ (see later).

In the "semicrystalline " case of flat platelets, the amplitude factors $A_{i}(Q)$ were first derived by Barnes [16] :

$$
\begin{aligned}
A_{i}(Q)=\frac{1}{N} \sum_{p=1}^{N} J_{0}(2 Q a \times \sin v & \left.\times \sin \frac{\pi p}{N}\right) \times \\
& \times \cos \left(\frac{2 \pi i p}{N}\right)
\end{aligned}
$$

where $v$ is the angle between $\mathbf{Q}\left(\mathbf{Q}=\mathbf{k}-\mathbf{k}_{\mathbf{0}}\right)$ and the axis of rotation. Therefore, we have oriented the platelets with angles equal to $3 \pi / 4$ and $\pi / 4$ with respect to the incident beam in order to discriminate between $Q$ parallel $\left(Q_{\|}\right)$and $Q$ perpendicular $\left(Q_{\perp}\right)$ spectra. However, one must take care in PDA $\mathrm{MnCl}_{4}$ that the axes of rotation of $\mathrm{NH}_{3}$ groups are tilted from the base planes with angles roughly equal to $60^{\circ}$ for one group and to $120^{\circ}$ for the other one [2]. For arbitrary $Q$ corresponding to a detector position at an angle of $2 \theta^{\circ}$ degrees $\left(\bar{Q}=\frac{4 \pi \sin \theta}{\lambda_{0}}\right)$ we thus obtain the following analytical expressions :

$$
\begin{aligned}
& A_{0}\left(Q_{\|} \text {for } 2 \theta^{\circ}\right)= \\
& =\frac{1}{2}\left\{\frac{1}{N} \sum_{p=1}^{N} J_{0}\left(2 Q a \sin \left(\theta^{\circ}+15^{\circ}\right) \sin \left(\frac{\pi p}{N}\right)\right)+\right. \\
& \left.+\frac{1}{N} \sum_{p=1}^{N} J_{0}\left(2 Q a \sin \left(\theta^{\circ}+75^{\circ}\right) \sin \left(\frac{\pi p}{N}\right)\right)\right\} \\
& A_{0}\left(Q_{\perp} \text { for } 2 \theta^{\circ}\right)= \\
& =\frac{1}{2}\left\{\frac{1}{N} \sum_{p=1}^{N} J_{0}\left(2 Q a \sin \left(75^{\circ}-\theta^{\circ}\right) \sin \left(\frac{\pi p}{N}\right)\right)+\right. \\
& \left.+\frac{1}{N} \sum_{p=1}^{N} J_{0}\left(2 Q a \sin \left(\theta^{\circ}-15^{\circ}\right) \sin \left(\frac{\pi p}{N}\right)\right)\right\}
\end{aligned}
$$

We can check easily that for the particular detector position at $2 \theta=90^{\circ}$, the angles $v$ between $Q$ and the axes of $\mathrm{NH}_{3}$ rotation are equal to $60^{\circ}$ and $120^{\circ}$ in the former case $\left(Q_{\|}\right)$while both angles $v$ are equal to $30^{\circ}$ in the latter one $\left(Q_{\perp}\right)$ as is expected from geometrical considerations (Fig. 3). The corresponding theoretical EISF curves obtained via the above relations and the expression (6), with the assumption that $\rho$ is again equal to 0.5 , are plotted on figure 4 . These curves apply to the $2 \pi / 3$ jump model but almost identical curves are obtained for the $2 \pi / 6$ model over the $0-2.5 \AA^{-1} Q$ range. Once more we cannot discriminate between both jump models but experimental points

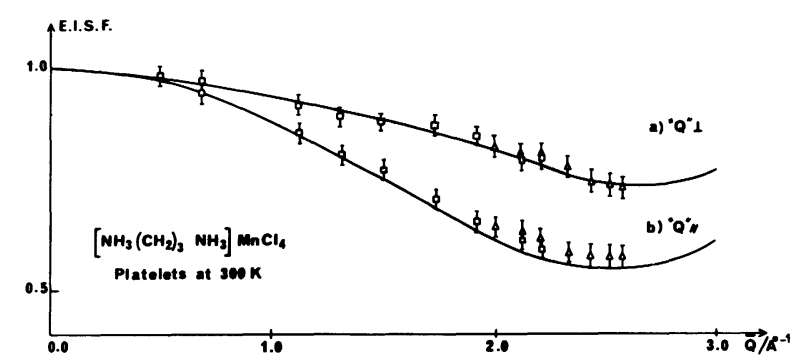

Fig. 4. - Comparison of the theoretical (full-lines) and experimental ( $\Phi$ points for $\lambda_{0}=5.14 \AA$ and $\Phi$ points for $\lambda_{0}=4.1 \AA$ ) EISF for $2 \pi / 3$ jumps of the $\mathrm{NH}_{3}$ groups and using oriented crystals of PDA $\mathrm{MnCl}_{4}, a$ ) results for the configuration " $Q$ perpendicular» (" $\left.\left.Q_{\perp} »\right), b\right)$ results for the configuration " $Q$ parallel $"\left(" Q_{\|} »\right)$. 
either for $Q_{\|}$or for $Q_{\perp}$ compare nicely with the theoretical curves and confirm that at about $300 \mathrm{~K}$ the mobile protons of PDA are those of the $\mathrm{NH}_{3}$ groups.

\section{Results and discussion.}

4. 1 BACK SCATtering ReSUlts. - A very weak broadening in the quasi-elastic region has been detected with the high resolution $(1 \mu \mathrm{eV})$ IN10 instrument using the partly deuterated $\left({ }^{6} \mathrm{H}-{ }^{6} \mathrm{D}\right)$ powder sample $\left(\mathrm{NH}_{3}\left(\mathrm{CD}_{2}\right)_{3} \mathrm{NH}_{3}\right) \mathrm{MnCl}_{4}$ at $280 \mathrm{~K}$ (Fig. 5). However, the weakness of this effect and the poor statistics prevent any significant analysis in order to determine the dynamical process in which the $\mathrm{NH}_{3}$ groups are involved. Moreover, the experimental profiles obtained with hydrogenated samples $\left({ }^{12} \mathrm{H}\right)$ differed slightly from those of the resolution. In any case, no tunnelling effect was observed at low temperature indicating that the potential barriers must be relatively high and insofar as these results are significant a correlation time $\tau_{\mathrm{c}}^{(280 \mathrm{~K})}$ of about $10^{-10}-10^{-11} \mathrm{~s}$ can be suggested. Moreover, we have measured the normalized elastic intensity without Doppler drive for different $Q$ values and over the whole temperature range $4-280 \mathrm{~K}$ in order to check whether a diffusional motion is really taking place. In such experiments the incident neutron beam is monochromatic and only the neutrons which do not display energy changes are backscattered. Thus, for nonzero $Q$ values the neutrons scattered with energy changes are not collected by the detectors and do not contribute to the elastic intensity. On figure 6, we have plotted $-\operatorname{Ln}\left(\right.$ Int. $_{\text {elast }}$ ) versus $Q^{2}$ at different temperatures using the normalizations with the run at $4 \mathrm{~K}$ and the monitor counting rates $\left(M_{1}\right)$. In fact, the ratios $\left(D_{i} / M_{1}\right)$ of the counting rates in the detector $D_{i}$ and in the monitor $1\left(M_{1}\right)$ have been measured in the temperature range $4-250 \mathrm{~K}$ and for

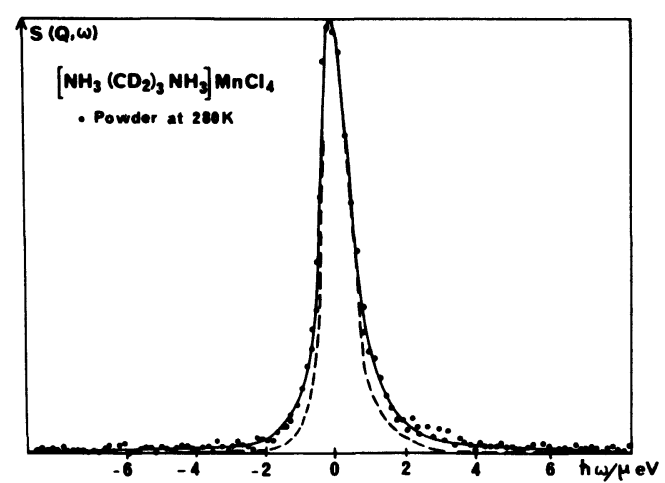

Fig. 5. - Comparison of the resolution (dotted line) and of the PDA $\mathrm{MnCl}_{4}\left({ }^{6} \mathrm{H}^{6} \mathrm{D}\right)$ spectra taken with a powdered sample at $4 \mathrm{~K}$ and $280 \mathrm{~K}$, respectively, on the backscattering IN10 spectrometer $\left(\lambda_{0}=6.28 \AA\right)$ for a scattering angle of $153^{\circ}\left(\bar{Q}=1.946 \AA^{-1}\right)$. The two peaks have been normalized to the same maximum intensity. The very weak broadening and the poor statistics prevent any quantitative analysis of the inelastic contribution which is expected to spread over a much larger energy range. each detector the variations of the elastic intensity were estimated with respect to the value of this ratio at $4 \mathrm{~K}$, i.e. Int. $_{\text {elast }}=\left(D_{i} / M_{1}\right)_{T} /\left(D_{i} / M_{1}\right)_{4 \mathrm{~K}}$. The nonlinear temperature dependence observed on these curves for $T \geqslant 85 \mathrm{~K}$ indicates that the usual DebyeWaller factor is not sufficient to explain the decreases of the elastic intensity. Thus, $\mathrm{NH}_{3}$ groups undergo a rotational motion leading to what appears as an unusual amplitude factor as soon as the first phase transition at $110 \mathrm{~K}$ is approached. Finally, we conclude that the weak broadening in the quasi-elastic region is connected with pure $\mathrm{NH}_{3}$ motions and that the energy transfer range for this scattering is much larger than $12.5 \mu \mathrm{eV}$ as soon as the $\mathrm{NH}_{3}$ groups start to jump. This weak effect is in agreement with the very small radius of gyration $(a<1.0 \AA)$ of $\mathrm{NH}_{3}$ groups.

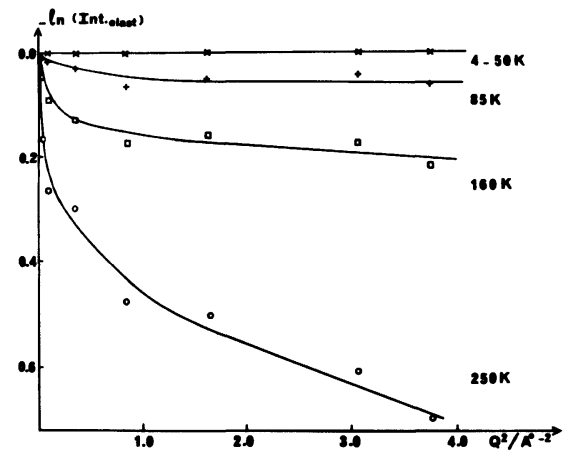

Fig. 6. - Variations of the elastic intensity versus $Q^{2}\left(/ \AA^{-2}\right)$ at different temperatures for a powdered sample of PDA $\mathrm{MnCl}_{4}$. In fact, the peak intensities have been normalized to the countings on the monitor 1 and compared with the ratio obtained at $4 \mathrm{~K}$ (see text).

4.2 TIME OF FLIGHT ReSUlTs. - TOF experiments on IN5 and IN6 instruments were carried out using different resolutions (Table II) in order to study the dynamics of $\mathrm{NH}_{3}$ groups near the room temperature phase III. Most of these experiments were performed on monocrystalline platelets and, as illustrated on figures 7 and 8, quasielastic broadenings are clearly observed essentially for configurations with $Q$ parallel to the base planes. Similarly, some spectra of a powder sample were analysed and quasi-elastic contributions were again detected mainly in the high $Q$ range, 1.7-2.2 $\AA^{-1}$ (Fig. 9).

The corrected IQENS spectra were fitted with those calculated by folding the scattering law for uniaxial rotational motion of $\mathrm{N}-\mathrm{H}$ protons with the instrumental resolutions. The parameters used in the fitting procedures are the following ones :

$F$ is a scaling or amplitude factor which normalizes the calculated intensity to the experimental function.

$B$ corresponds to an inelastic background correction of the base line, which may be proportional to $Q$ or $Q^{2}$, and which, eventually, takes into account a nonnegligible multiple scattering contribution. 

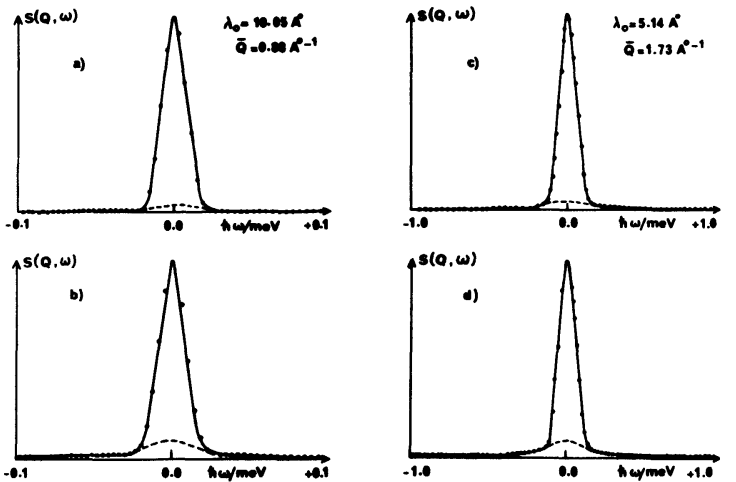

Fig. 7. - Comparison of two sets of quasi-elastic neutron scattering spectra recorded on the time of flight IN5 instrument using different orientations of monocrystalline platelets of PDA $\mathrm{MnCl}_{4}$ with respect to the incident beam : a) and $b$ ) $\lambda_{0}=10.05 \AA$ and $Q=0.88 \AA^{-1}$ for perpendicular and parallel orientations, respectively, $c$ ) and $d) \lambda_{0}=5.14 \AA$ and $Q=1.73 \AA^{-1}$ for perpendicular and parallel orientations, respectively. The dotted lines indicate the quasi-elastic broadening contributions.
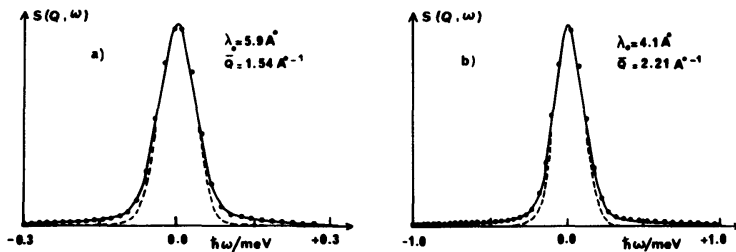

Fig. 8. - Quasi-elastic neutron scattering spectra recorded on the time of flight IN6 instrument with $a) \lambda_{0}=5.9 \AA$ $\left(Q=1.54 \AA^{-1}\right)$ and $\left.b\right) \lambda_{0}=4.1 \AA\left(Q=2.21 \AA^{-1}\right)$ and using oriented crystals of PDA $\mathrm{MnCl}_{4}$ in the " $Q$ parallel " configuration. In each case the experimental spectrum is compared with the vanadium elastic peak (dotted lines).

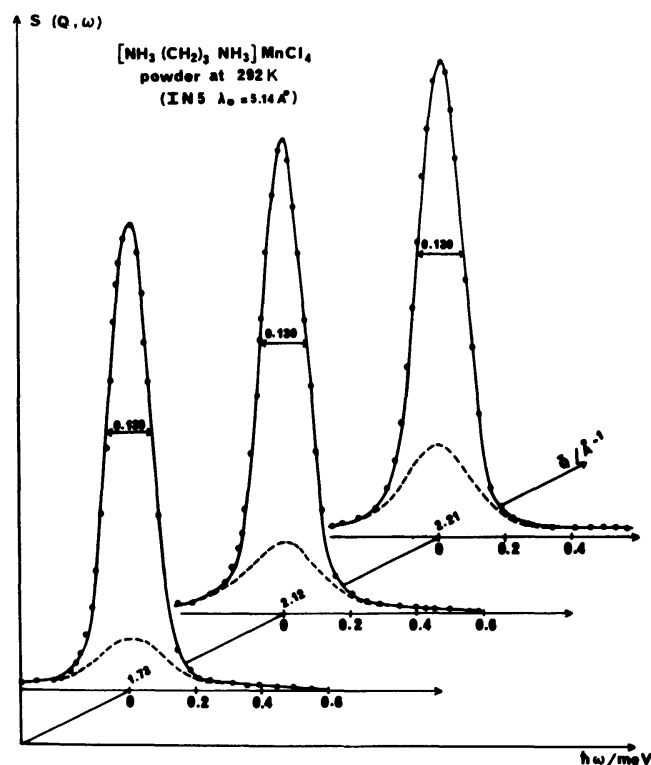

Fig. 9. - Corrected quasi-elastic neutron scattering spectra for polycrystalline samples of PDA $\mathrm{MnCl}_{4}$ at $292 \mathrm{~K}$ taken on the IN5 spectrometer with $\lambda_{0}=5.14 \AA$ for different $Q$ values $\left(1.73,2.12\right.$ and $2.21 \AA^{-1}$, respectively). The dotted lines represent the quasi-elastic contributions. $\left\langle u^{2}\right\rangle$ is the mean square vibrational amplitude of the projection of the proton displacements on $\mathbf{Q}$; it appears in the Debye-Waller factor, $\exp \left(-Q^{2}\left\langle u^{2}\right\rangle\right)$.

$\rho$ is the ratio of the number of fixed protons to the total number of protons.

$D_{\mathrm{r}}$ is a parameter governing the width of the first Lorentzian of the scattering function and is equal to $\left(\tau_{1}^{-1}\right)$; thus, $\tau_{\mathrm{c}}$ values are derived through the relation (5).

$a$ is the radius of gyration of mobile $\mathrm{N}-\mathrm{H}$ protons and has been estimated from neutron diffraction results [2]. This parameter was always observed to tend to the expected value, $0.942 \AA$.

$N$ is the number of equivalent sites for the protons on the circle of radius $a$.

$v$ is the angle between $\mathbf{Q}$ and the axes of rotation of $\mathrm{NH}_{3}$ groups for platelet experiments.

Using equations (2) and (3) one obtains the general expression (10) for the scattering law :

$$
\begin{aligned}
S_{\text {inc }}(Q, w)=F \exp \left(-Q^{2}\left\langle u^{2}\right\rangle\right) \times \\
\times\left\{\left[\rho+(1-\rho) A_{0}(Q)\right] G(w)+(1-\rho) \frac{1}{\pi} \times\right. \\
\left.\times\left[\sum_{i=1}^{N-1} A_{i}(Q) L\left(\tau_{i}^{-1}\right)\right] \otimes G(w)\right\}+B(Q)
\end{aligned}
$$

where the characteristic times $\tau_{i}$ are defined in equation (5) and $G(w)$ is the elastic resolution function measured for each scattering angle $(\otimes$ represents the convolution product). For IN5 spectra $G(w)$ is replaced in the convolution product by a triangular function having a width equal to the width averaged over all the scattering angles. A further complication comes from the fact that for a TOF instrument, at a given scattering angle, the resolution width varies with the energy transfer, $\hbar w$. This is taken care of in the evaluation of equation (10). The fitting procedure was first performed for each angle, and then a new set of input parameters was introduced in order to fit all the angles at the same time. Finally, the results of the different fits were compared as the incident wavelength was changed.

It is clear that the theoretical models for $2 \pi / 3$ and $2 \pi / 6$ jumps have led to the best consistency for all the data. Some fits using the theoretical model of $2 \pi / 2$ jumps of the alkylene chains were tried without success. In the same way, the ratio $\rho$ was always found to tend towards 0.5 . In this respect, the model of reorientations of PDA as a whole (corresponding to the value $\rho=0.0$ ), as suggested from broadline NMR results [2], was tried but no convergence was observed. In table III we report the final $D_{\mathrm{r}}$ values $(\mathrm{meV})$ obtained for the best fits at different temperatures, wavelengths and orientations of the platelets. The agreement between these values is satisfactory. For instance, whatever the orientation of the platelets, $D_{r}$ at $300 \mathrm{~K}$ is found equal to $0.092 \mathrm{meV}$ for $\lambda_{0}=5.14 \AA$ (IN5) or to $0.091 \mathrm{meV}$ for $\lambda_{0}=5.9 \AA$ (IN6). From these values, the corre- 
Table III. - Results of the different fits within the $2 \pi / 3$ jump model of $\mathrm{NH}_{3}$ groups in PDA $\mathrm{MnCl}_{4}$.

\begin{tabular}{|l|c|c|c|c|c|c|}
\hline \multicolumn{1}{|c|}{ Compound } & Instrument & $\begin{array}{c}\text { Incident } \lambda_{\mathbf{0}} \\
(\AA)\end{array}$ & $\begin{array}{c}\text { Temperature } \\
(\mathrm{K})\end{array}$ & $D_{\mathrm{r}}(\mathrm{meV})\left({ }^{\mathrm{b}}\right)$ & $\tau_{1} \times 10^{12}(\mathrm{~s})\left(^{\left({ }^{a}\right.}\right)$ & $\tau_{\mathrm{c}} \times 10^{12}(\mathrm{~s})\left(^{{ }^{a}}\right)$ \\
\hline Powder & IN5 & 5.14 & 292 & 0.064 & 10.29 & 15.43 \\
Platelets & IN5 & 5.14 & 275 & 0.034 & 19.36 & 29.04 \\
$\left(Q_{\|}\right.$and $\left.Q_{\perp}\right)$ & IN5 & 5.14 & 301 & 0.093 & 7.10 & 10.67 \\
- & IN5 & 10.05 & 304 & 0.100 & 6.58 & 9.87 \\
& IN6 & 4.1 & 299 & 0.092 & 7.15 & 10.73 \\
& IN6 & 5.9 & 299 & 0.091 & 7.20 & 10.80 \\
\hline
\end{tabular}

( $\left.{ }^{a}\right) \tau_{1}(\mathrm{~s})=\frac{0.658 \times 10^{-12}}{D_{\mathrm{r}}(\mathrm{meV})}$ and $\tau_{\mathrm{c}}=\tau_{1} \times 2 \sin ^{2}(\pi / 3)=\tau_{1} \times 1.5$.

(b) $D_{\mathrm{r}}$ is the HWHM of the first Lorentzian in the expression of $S_{\text {inc }}^{\text {rot }}(Q, w)$. The values reported here are those which give the best fits.

lation times $\tau_{\mathrm{c}}$ were derived over the $275-304 \mathrm{~K}$ temperature range. The figure 10 shows that their temperature dependence seems to follow an Arrhenius type law, $\tau_{\mathrm{c}}=\tau_{\infty} \exp \left(E_{\mathrm{A}} / K T\right)$. The correlation time at $300 \mathrm{~K}$ is found equal to $1.0 \times 10^{-11} \mathrm{~s}$ while the activation energy deduced from the slope of the Arrhenius plot is equal to $26.6 \mathrm{~kJ} / \mathrm{mol}$. In fact, this energy value is a rough estimate since it has only been obtained over a restricted temperature range (Table III).

\section{Conclusions.}

The consistency between all the above results obtained using several incident wavelengths and different temperature ranges allows us to propose reliable conclusions. We confirm that reorientational movements of only the protons of $\mathrm{NH}_{3}$ groups are taking place in phases III and IV of PDA $\mathrm{MnCl}_{4}$. This result is in agreement with Deuteron-NMR-NQR results [5] but in disagreement with broadline proton NMR conclusions. Also in our previous Raman study [7] some large amplitude librational movements of the alkylene chains coupled with $\mathrm{NH}_{3}$ torsions had been suggested. We conclude also that the dynamics of $\mathrm{NH}_{3}$ groups in the room temperature phase III are governed by a correlation time $\tau_{\mathrm{c}}^{300 \mathrm{~K}} \simeq 1 \times 10^{-11} \mathrm{~s}$ and by an activation energy of $26.6 \mathrm{~kJ} / \mathrm{mol}$. We are not able to descrimate between the $2 \pi / 3$ and $2 \pi / 6$ jump models over the $Q$ range investigated but the $2 \pi / 3$ model is physically the most probable. In this respect the activation energy can be compared with the $V_{3}$ potential barrier against the torsion as deduced from the torsional frequency $V_{3}^{0}=20.08 \mathrm{~kJ} \cdot \mathrm{mol}^{-1}$. Therefore, these IQENS results show that the activation energy derived from the Raman band broadenings [7] is once more $[18,19]$ underestimated and that the temperature dependence of Raman band widths cannot be satisfactorily interpreted within a simple Arrhenius type law.

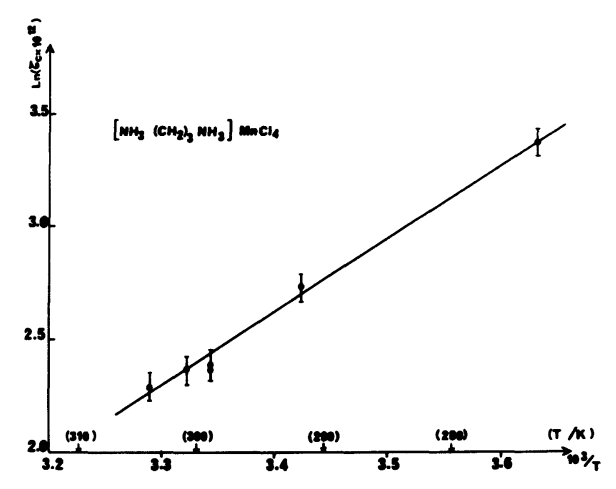

Fig. 10. - Arrhenius plot of the correlation times $\left(\tau_{\mathrm{c}}\right)$ against reciprocal temperatures (in the narrow range 275-304 K). The slope of the straight line gives an estimate of the activation energy for $\mathrm{NH}_{3}$ rotation.

Finally, it is noteworthy that the dynamics of $\mathrm{NH}_{3}$ groups in phase IV could be determined using the wide $Q$ range available on the IN13 instrument [11]. We also plan to perform additional experimental work at higher temperature. It would be interesting to check if a dynamical disorder of the chains between two orientations with the same or with different probabilities in time really exists in the crystalline phases I and II of PDA $\mathrm{MnCl}_{4}$. Experiments with the deuterated derivative $\left(\mathrm{ND}_{3}\left(\mathrm{CH}_{2}\right)_{3} \mathrm{ND}_{3}\right) \mathrm{MnCl}_{4}$ would be surely conclusive.

\section{Acknowledgments.}

The authors are thankful to J. Belloc, K. Chhor and C. Poinsignon for their participations in the experimental part of this work. Dr. M. Bee and Dr. J. C. Lassègues are also acknowledged for several helpful comments and fruitful discussions. 


\section{References}

[1] (a) Blinc, R., Burgar, M., Lozar, B., Seliger, J. Slak, J., Rutar, V., AREND, H. and KIND, R., J. Chem. Phys. 66 (1977) 278;

(b) BABerschke, K., Rys, F. and Arend, H., Physica $B-C$ 86-88 (1977) 685;

(c) Losee, D. B., McGregor, K. T., Estes, W. E. and HATField, W. E., Phys. Rev. B 14 (1976) 4100.

[2] Willett, R. D. and Riedel, E. F., Chem. Phys. 8 (1975) 112.

[3] Arend, H., Tichy, K., Baberschke, K. and Rys, F., Solid. State Comm. 18 (1976) 999.

[4] AREND, H. and Granicher, H., Ferroelectrics 13 (1976) 537.

[5] Kind, R., Plesko, S. and Roos, J., Phys. Status Solidi A 47 (1978) 233.

[6] Sourisseau, C. and Lucazeau, G., in Proceedings of the 6th International Conference on Raman Spectroscopy, Bangalore, India, 1978, p. 384, HeydenLondon (1978).

[7] Sourisseau, C. and Lucazeau, G., J. Raman Spectrosc. 8 (1979) 311.

[8] Sourisseau, C., Lucazeau, G., Poinsignon, C. and DiANOUX, A. J., ILL annual report (1980) no 9-03246, p. 407.
[9] Sourisseau, C., Lucazeau, G. and Dianoux, A. J. ILL annual report (1981) $\mathrm{n}^{\circ} 0-93-261$, p. 297 and no 9-03-261 bis, p. 298.

[10] Belloc, J. and LaUtie, M. F., unpublished results.

[11] Neutron Scattering Facilities at the HFR, Grenoble (1981). Copies may be obtained from the Scientific Secretary, ILL Grenoble, France.

[12] Howells, W. S., ILL Internal Technical reports $75 \mathrm{H} 130$ and $76 \mathrm{H} 122$ (1977).

[13] Dianoux, A. J., Ghosh, R. E., Hervet, H. and LeChNER, R. E., ILL Internal Technical report 75 D 16 T (1975).

[14] Dianoux, A. J. and Volino, F., Mol. Phys. 34 (1977) 1263.

[15] Dianoux, A. J., Volino, F. and Hervet, H., Mol. Phys. 30 (1975) 1181.

[16] Barnes, J. D., J. Chem. Phys. 58 (1973) 5193.

[17] A detailed discussion of the EISF may be found in LEADBETTER, A. J. and LeCHNER, R. E., Chapter 8 in The Plastically Crystalline State, Ed. J. N. Sherwood, J. Wiley and Sons, 1979, p. 285-320.

[18] Sourisseau, C., Lucazeau, G., Dianoux, A. J. and Poinsignon, C., Mol. Phys. 48 (1983) 367.

[19] Lucazeau, G., ChHor, K., Sourisseau, C. and Dianoux, A. J., Chem. Phys. 76 (1983) 307. 